\title{
Adolescent mental health education InSciEd Out: a case study of an alternative middle school population
}

\author{
Joanna Yang ${ }^{1}$, Roberto Lopez Cervera ${ }^{2}$, Susannah J. Tye ${ }^{3}$, Stephen C. Ekker ${ }^{1,4}$ and Chris Pierret ${ }^{1,4^{*}}$ (1)
}

\begin{abstract}
Background: Mental illness contributes substantially to global disease burden, particularly when illness onset occurs during youth and help-seeking is delayed and/or limited. Yet, few mental health promotion interventions target youth, particularly those with or at high risk of developing mental illness ("at-risk"youth). Community-based translational research has the capacity to identify and intervene upon barriers to positive health outcomes. This is especially important for integrated care in at-risk youth populations.

Methods: Here the Integrated Science Education Outreach (InSciEd Out) program delivered a novel school-based anti-stigma intervention in mental health to a cohort of seventh and eighth grade at-risk students. These students were assessed for changes in mental health knowledge, stigmatization, and help-seeking intentions via a classroom activity, surveys, and teacher interviews. Descriptive statistics and Cohen's d effect sizes were employed to assess prepost changes. Inferential statistical analyses were also conducted on pilot results to provide a benchmark to inform future studies.
\end{abstract}

Results: Elimination of mental health misconceptions (substance weakness $p=0.00$; recovery $p=0.05$; prevention $p=0.05$; violent $p=0.05)$ was accompanied by slight gains in mental health literacy $(d=0.18)$ and small to medium improvements in help-seeking intentions (anxiety $d=0.24$; depression $d=0.48$; substance $d=0.43$; psychosis $d=0.53$ ). Within this particular cohort of students, stigma was exceptionally low at baseline and remained largely unchanged. Teacher narratives revealed positive teacher views of programming, increased student openness to talk about mental illness, and higher peer and self-acceptance of mental health diagnoses and help-seeking.

Conclusions: Curricular-based efforts focused on mental illness in an alternative school setting are feasible and integrated well into general curricula under the InSciEd Out framework. Preliminary data suggest the existence of unique help-seeking barriers in at-risk youth. Increased focus upon community-based programming has potential to bridge gaps in translation, bringing this critical population to clinical care in pursuit of improved mental health for all.

Trial registration ClinicalTrials.gov, ID:NCT02680899. Registered 12 February 2016, https://clinicaltrials.gov/ct2/show/ NCT02680899

Keywords: Mental health, (alternative) Education, Stigma, School-based, Adolescent

\footnotetext{
${ }^{*}$ Correspondence: pierret.christopher@mayo.edu

${ }^{1}$ Clinical and Translational Science, Mayo Clinic, Rochester, MN, USA

Full list of author information is available at the end of the article
} 


\section{Background}

\section{The priority of mental health}

Prevention and treatment of mental illness remain significantly underserved health needs, despite poor mental health being of worldwide concern [1]. Youth are uniquely vulnerable, as most mental illnesses have early onset [2]. Effective help-seeking remains low, and attitudinal barriers - particularly stigma and inadequate mental health literacy-are commonplace [3]. Regardless of established need, few stigma-reduction programs target adolescents [4], and broader promotion-prevention interventions are lacking [2]. Youth-centric programming is therefore a critical need given the formative and persistent role of adolescence in development.

\section{Theoretical frameworks to break down the barriers}

While structural barriers to mental healthcare exist for broader policy intervention, knowledge and attitudes are readily addressable at the individual level. Improvements have been made in recent years to both study and bolster the public's mental health literacy, but dissemination of accurate information remains a necessary focus for betterment of mental health $[5,6]$. This is particularly true for youth, where mental health literacy efforts have traditionally been flagging [7]. One theoretical framework often applied to health interventions is the knowledgeattitude-behavior (KAB) model. In this model, increased knowledge can change attitudes and result in behavioral modification [8, 9]. The knowledge-attitude-behavior continuum plays a key role in modern definitions of mental health literacy with evidence to suggest that improved knowledge and reduced stigma can result in increased help-seeking and improved outcomes in mental health [10]. Meta-analysis additionally shows that educational programming can alter stigma toward mental illness, particularly for youth audiences [11].

Traditional health education at the bedside only works, however, if patients enter healthcare systems in the first place. Underserved populations who tend to not seek care may therefore be better reached though community-based methods $[12,13]$. For youth, K-12 classrooms represent a unique community platform in health intervention due to the significant amount of time youth spend in school [14]. Yet, there is insufficient evidence for efficacy of school-based anti-stigma programming pertaining to mental illness [15]. Interventions targeting youth with mental illness or at high risk for developing mental illness are rare and comparatively unstudied. Lack of research evidence in this space is a priority, as it contributes to care fragmentation. Translational research is necessary to bridge the gap from bedside to curbside for the most vulnerable children and adolescents [16]. The study herein presents preliminary results from a school-based anti-stigma intervention in mental health piloted by one such translational program called Integrated Science Education Outreach (InSciEd Out).

\section{The InSciEd Out framework}

InSciEd Out [17] is an intracurricular partnership that connects K-12 teachers with scientists and other health professionals to design school-based units targeting salient health topics. These units give real world context to selected state standards taught in the classroom and replace previous curricula targeting these standards. Under this novel framework, a foundation of science excellence for all students $[18,19]$ is extended to address student learning related to health, disseminating health education into the community. Because of this, InSciEd Out is a truly translational program that capitalizes upon longitudinal community engagement to help test, interpret, implement, and assess the impact of knowledge. These data transfer elements address a spectrum of translational science aimed toward behavioral changes and improved public health [20].

The InSciEd Out program is a community-based participatory research model where health topics of focus are chosen in collaboration with partnering schools and their community leaders. Selected teacher partners undergo a 12-day scientific and pedagogical internship before collaborating to design, implement, and assess their health-focused units. One key aspect of the produced lessons is that students are encouraged to be active creators rather than passive consumers of knowledge. This student-driven inquiry is at the heart of the health literacy that InSciEd Out fosters. Clinically-focused interventions using InSciEd Out's health-related curricula are called prescription education [21] and are driven in part by the KAB health model. InSciEd Out's mental health arm consequently seeks to improve attitudes and downstream behaviors toward mental illness through addressing mental health literacy.

Longitudinal study of InSciEd Out reveals sustained gains in science literacy, demonstrating capability of InSciEd Out-facilitated knowledge transfer [19]. An initial assessment of prescription education in influenzafocused curriculum found improvements in unprompted knowledge of preventative behaviors [21].

\section{Methods \\ Study design}

This pilot study presents findings from the inaugural run of InSciEd Out prescription education curriculum in mental health. Its quasi-experimental design follows a single cohort of seventh and eighth grade students at an InSciEd Out partner public alternative school in the Midwestern U.S. While alternative education is a broad 
term encompassing all nontraditional educational programming [22], the study school here voluntarily admits its $\sim 350$ students (grades 7-12) based on entrance criteria that include potential chemical dependence or mental health issues. These students are "at-risk" youth, defined as youth with diagnosed/diagnosable mental illness or who have a high likelihood of developing mental illness.

The intervention was a 20-day anti-stigma classroom experience in the 2015-2016 school year. Intervention lessons replaced non-mental health focused lessons addressing selected state standards in science, math, and language arts. The intervention unit culminated with mentored science research projects based on studentdriven questions in mental health. One highlight of this curriculum was its integration of biogenetic explanations of mental illness with broader social and cultural context through a combination of education and contact programming (Table 1).

\section{Assessing student outcomes}

This case study was hypothesis-generating by design due to its novel population. Nevertheless, it aimed to test the premise that students undergoing InSciEd Out mental health curriculum exhibit pre-post increases in mental health literacy, decreases in mental illness stigmatization, and increases in hypothetical mental health help-seeking behavioral intentions. Study metrics were chosen to align with the KAB theoretical framework. Classroom activities and student surveys were administered pre-post intervention. Pilot status, novelty, and lack of a comparable partner school drove the decision to not recruit an external control.

\section{Misconceptions activity}

A curriculum-embedded activity on mental health misconceptions used anonymous student polling to assess preliminary, cohort-level mental health literacy. Anonymous cohort polling precluded matched analyses. The activity incorporated ten misconceptions assembled from websites of repute [23-26] grouped into three categories, covering mental illness: (1) being fictitious, irrelevant, and caused by personal weakness (generally and specifically for substance use and depression); (2) having no recovery and no prevention; and (3) causing patients to be violent/unpredictable, be unintelligent, and need separation in healthcare.

\section{Mental health surveys}

Three previously published and validated adolescent surveys totaling 28 questions were selected to assess mental health knowledge, stigmatization, and help-seeking behavioral intentions. Reliability and validity testing were not completed in the study population due to restricted sample size and lack of a comparable population for validation.

There is no gold standard mental health knowledge inventory, particularly for youth. Here the study used the Westbrook Mental Health Knowledge Test (WMHKT), a 13-question, true/false/not sure survey on knowledge of generalized mental health [27]. Analysis primarily concerned correctness of response without distinguishing between incorrect and "not sure" responses.

To assess whether knowledge changes were accompanied by attitudinal change, the Adolescent Attribution Questionnaire (AQ-8-C) measured stigmatizing attitudes $[27,28]$. The AQ-8-C is the short-form, eight-question attribution questionnaire for assessment of public stigma. It measures stereotypes of blame, anger, pity, help, dangerousness, fear, avoidance, and segregation. Each question is rated on a 9-point Likert scale with question 7 (help) reverse coded. Higher scores indicate higher stigma, so pre-post change shows stigma reduction when

Table 1 Lesson components and target concepts

\begin{tabular}{|c|c|c|c|}
\hline & Lesson & Target concepts & Strategies \\
\hline Day 1 & Introduction & Pre-evaluation and introductory activities & $\begin{array}{l}\text { Engage } \\
\text { Evaluate }\end{array}$ \\
\hline Days $2-5$ & My brain and I & $\begin{array}{l}\text { Biogenetic foundations (brain anatomy and neurotransmission) and psychosocial foundations (mental } \\
\text { healthcare system and barriers) to explore topics of resiliency and nature vs. nurture }\end{array}$ & $\begin{array}{l}\text { Explore } \\
\text { Contact }\end{array}$ \\
\hline Days 6-15 & Mental health and I & $\begin{array}{l}\text { Mental health research projects, experimental design and hypothesis generation, execution of scientific } \\
\text { experiments, data analysis, creation of mental health promotion art }\end{array}$ & $\begin{array}{l}\text { Explain } \\
\text { Elaborate } \\
\text { Extend }\end{array}$ \\
\hline Days 16-18 & $\begin{array}{l}\text { Sharing my voice } \\
\text { in mental health }\end{array}$ & $\begin{array}{l}\text { Organization of mental health scientific research and artistic voice into multimedia presentation to } \\
\text { share a personal story }\end{array}$ & $\begin{array}{l}\text { Explain } \\
\text { Elaborate } \\
\text { Extend }\end{array}$ \\
\hline Days 19-20 & Conclusion & Post-evaluation and conclude activities & $\begin{array}{l}\text { Explain } \\
\text { Evaluate }\end{array}$ \\
\hline
\end{tabular}

The InSciEd Out mental health unit in this study first built a foundation of knowledge in mental health before facilitating student exploration of mental health topics with personal relevance 
negative. Primary analysis concerned overall stigma score with secondary analysis of each stereotype.

Lastly, the General Help-Seeking Questionnaire Vignette Version (GHSQ-V) was administered to assess whether knowledge and attitude changes extended to changes in intended behavioral modification. The GHSQ$\mathrm{V}$ measures help-seeking intentions, health literacy, and perceived need for help [29]. Seven vignettes for different health conditions are posed, and respondents indicate their intention to seek help via 7-point Likert scales. Various help sources are queried for each scenario, and additional fields are provided for respondents to give a diagnosis (literacy) and to indicate whether they think the individual in the vignette needs help (perceived need). Preliminary analysis to generate a summative score for the GHSQ-V revealed highest scale reliability with exclusion of item I "would not see help" (Table 2). Missing responses were therefore filled in with the average value of responses in $\mathrm{A}-\mathrm{H}$ (all other help sources) to facilitate total scoring. Help sources were not split into formal and informal sources due to small sample size and scale reliability. Analysis of fill-in responses for diagnoses accepted schizophrenia for psychosis, any reference to alcohol or drugs for substance misuse, and heart attack or stroke for heart disease.

\section{Teacher exit interviews}

Semi-structured interviews were conducted post-curricular implementation with the two partner teachers to capture a larger narrative of student change. Questions were designed to explore teachers' perceptions of (1) the curriculum, (2) metrics for assessing curricular effect, and (3) changes in student knowledge, attitudes, and behaviors. Interviews were recorded and transcribed before primary coding by two independent coders.
Resultant coding was compared and condensed into a final coding manual for secondary coding into emerging themes.

\section{Statistical analyses}

Of 19 eligible students, 14 assented to formal pre- and post-survey assessments. All participating teachers consented to interviews. Due to small sample size, primary results largely refer to changes in response distribution (average \pm standard deviation, unless otherwise indicated). Effect sizes were calculated as Cohen's d values from $d=\frac{M_{\text {post }}-M_{\text {pre }}}{S D_{\text {pooled }}}$, where $S D_{\text {pooled }}=\sqrt{\frac{S D_{\text {pre }}^{2}+S D_{\text {post }}^{2}}{2}}$.

They are included for subscales for thoroughness but are subject to potentially low reliability and should be interpreted with caution. To supplement these descriptive statistics, inferential statistics were also conducted to provide a benchmark for future studies. Statistical tests were performed in JMP Pro 12 (2015). To be conservative, two-tailed p-values are reported. Misconceptions data was analyzed via Fisher's exact test due to incompletely matched samples; average change in response on each survey inventory was assessed by Wilcoxon signed rank tests due to variable normality and small sample size.

\section{Results}

\section{Mental health knowledge}

The classroom activity, surveys, and teacher interviews painted a narrative of curricular effects. First, the misconceptions activity showed significant elimination of student misconceptions of mental illness (Table 3). At baseline, at least one student present indicated agreement with every misconception posed besides separation. By post-evaluation, none of the students present still

Table 2 Creation of a summative score for the GHSQ-V

\begin{tabular}{|c|c|c|c|c|c|c|c|c|c|c|c|c|c|c|}
\hline & \multicolumn{2}{|l|}{ Stress } & \multicolumn{2}{|c|}{ Anxiety } & \multicolumn{2}{|c|}{ Depression } & \multicolumn{2}{|c|}{ Suicidal ideation } & \multicolumn{2}{|c|}{$\begin{array}{l}\text { Substance } \\
\text { misuse }\end{array}$} & \multicolumn{2}{|c|}{ Psychosis } & \multicolumn{2}{|c|}{ Heart disease } \\
\hline & Pre & Post & Pre & Post & Pre & Post & Pre & Post & Pre & Post & Pre & Post & Pre & Post \\
\hline None & 0.7471 & 0.6552 & 0.8473 & 0.6629 & 0.8523 & 0.8246 & 0.9189 & 0.7646 & 0.8645 & 0.6484 & 0.8550 & 0.6907 & 0.7627 & 0.6492 \\
\hline A & 0.7277 & 0.6415 & 0.8459 & 0.6048 & 0.8311 & 0.7955 & 0.8985 & 0.7998 & 0.8551 & 0.7109 & 0.8597 & 0.7055 & 0.7622 & 0.5987 \\
\hline B & 0.6967 & 0.6077 & 0.8189 & 0.6013 & 0.8314 & 0.8021 & 0.9045 & 0.7554 & 0.8729 & 0.6656 & 0.8505 & 0.6687 & 0.7178 & 0.5813 \\
\hline C & 0.7417 & 0.5851 & 0.8457 & 0.6998 & 0.8625 & 0.8101 & 0.9187 & 0.7496 & 0.8691 & 0.5883 & 0.8427 & 0.6818 & 0.7894 & 0.7110 \\
\hline $\mathrm{D}$ & 0.6785 & 0.5776 & 0.8197 & 0.5603 & 0.8195 & 0.8168 & 0.8949 & 0.7154 & 0.8270 & 0.6083 & 0.8375 & 0.6465 & 0.6990 & 0.5041 \\
\hline$E$ & 0.7456 & 0.5987 & 0.8162 & 0.5516 & 0.8357 & 0.7757 & 0.9041 & 0.6841 & 0.8172 & 0.5216 & 0.8174 & 0.6101 & 0.7102 & 0.4819 \\
\hline$F$ & 0.6904 & 0.5664 & 0.8318 & 0.6164 & 0.8356 & 0.7828 & 0.9126 & 0.7008 & 0.8303 & 0.6220 & 0.8355 & 0.6871 & 0.6929 & 0.5739 \\
\hline G & 0.7153 & 0.6488 & 0.8302 & 0.6286 & 0.8353 & 0.7818 & 0.9096 & 0.7004 & 0.8283 & 0.5478 & 0.8328 & 0.5879 & 0.7597 & 0.6539 \\
\hline $\mathrm{H}$ & 0.7775 & 0.6425 & 0.8601 & 0.6606 & 0.8376 & 0.8164 & 0.9097 & 0.7435 & 0.8700 & 0.6271 & 0.8489 & 0.6984 & 0.7576 & 0.6256 \\
\hline I & 0.7208 & 0.7361 & 0.8046 & 0.7367 & 0.8390 & 0.8638 & 0.9298 & 0.7967 & 0.8629 & 0.6381 & 0.8281 & 0.6679 & 0.7445 & 0.7436 \\
\hline
\end{tabular}

Cronbach's alphas support exclusion of item "I" (reverse coded) to maximize scale reliability. Iterative reliability is calculated for the full scale and partial scales excluding each item. The option with highest reliability in each column is italicized 
Table 3 Mental illness misconceptions

\begin{tabular}{|c|c|c|c|}
\hline & $\begin{array}{l}\text { Pre } \\
n=18(\%)\end{array}$ & $\begin{array}{l}\text { Post } \\
n=18(\%)\end{array}$ & $\begin{array}{l}\text { Fisher's } \\
\text { p-value }\end{array}$ \\
\hline S1: Mental illnesses are not real illnesses & 5.6 & 0.0 & 1.0000 \\
\hline S2: Mental illness will never affect me & 5.6 & 0.0 & 1.0000 \\
\hline S3: People with mental illnesses are violent and unpredictable & 27.8 & 0.0 & 0.0455 \\
\hline S4: Mental illness is caused by personal weakness & 11.1 & 0.0 & 0.4857 \\
\hline S5: Addicts who cannot quit simply lack willpower & 61.1 & 0.0 & $0.0001^{*}$ \\
\hline S6: A person who is depressed is just not trying hard enough to snap out of it & 11.1 & 0.0 & 0.4857 \\
\hline S7: There is no recovery for people with mental health problems & 27.8 & 0.0 & 0.0455 \\
\hline S8: It is impossible to lower the risk for developing mental illness & 27.8 & 0.0 & 0.0455 \\
\hline S9: People with mental illness should be hospitalized away from other patients & 0.0 & 0.0 & 1.000 \\
\hline S10: People with mental illness lack intelligence & 22.2 & 0.0 & 0.1039 \\
\hline
\end{tabular}

Students eliminate mental illness misconceptions post-InSciEd Out curriculum. Statements with significant change are italicized, and the statement that remains significant under multiple comparisons adjustment is asterisked

agreed with any of the misconceptions, demonstrating with statistical significance $\left(x^{2}, p=0.00-0.05\right)$ for four of the statements posed that the InSciEd Out curriculum lowered students' mental health misconceptions. After Bonferroni correction, misconception elimination for statement 5 was still statistically significant.

Analysis of the Westbrook Mental Health Knowledge Test partially corroborated this trend toward gains in mental health literacy. There was a shift toward higher post-scores in the negative skewness of the data (Fig. 1a). Individual item analysis of the number of students answering each question correctly (Fig. 1b) revealed that the largest gains were in questions 2 ("mental illness is like other diseases because a person who has it has symptoms that a doctor can diagnose") and 4 ("the brain of a healthy person works the same as that of a mentally ill person"). Conversely, students scored poorest on question 11, which asked if "depression is a disease."
Matched change showed a $0.43 \pm 2.59$ increase in overall mental health knowledge from pre- $(8.14 \pm 2.07$, median $8)$ to post- $(8.57 \pm 2.71$, median 9.5$)$ that was not statistically significant with an effect size of $d=0.18$. GHSQ-V vignette identification was variable at baseline ( stressed $=7 \%$; psychosis $=21 \%$; heart disease $=21 \%$; anxiety $=29 \%$; suicidal $=36 \%$; depression $=43 \%$; substance $=64 \%$ ) and comparable at post-evaluation, excepting improvement in depression recognition $(+36 \%)$.

\section{Mental illness stigmatization}

The AQ-8-C extended results in knowledge to attitudinal shifts. Analysis revealed low baseline stigma that remained largely unchanged (Fig. 2a). This low baseline left nearly no room for stigma decrease postintervention. Stigma was particularly low for the items of blame, segregation, and anger. The largest changes
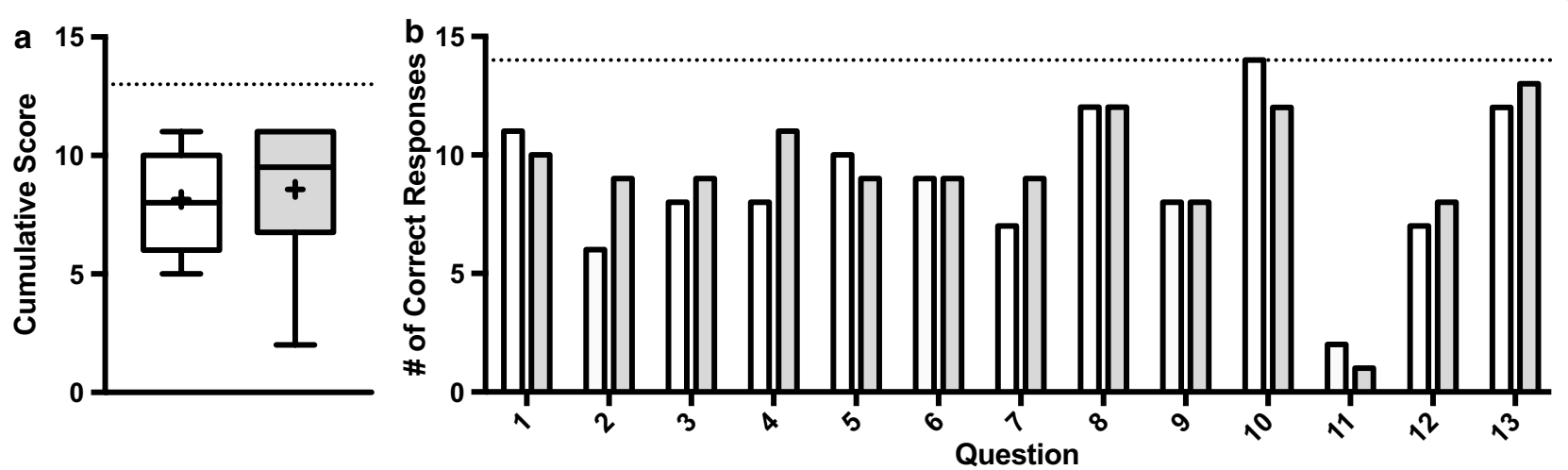

Fig. 1 Westbrook Mental Health Knowledge Test. Students trend toward gains in mental health knowledge on the Westbrook Mental Health Knowledge Test post-intervention. Pre-scores are white; post-scores are grey; dotted lines indicate maximum possible score; "+ "is the mean. a Cumulative score distribution. b Number of correct student responses, out of 14 eligible students, for each question 

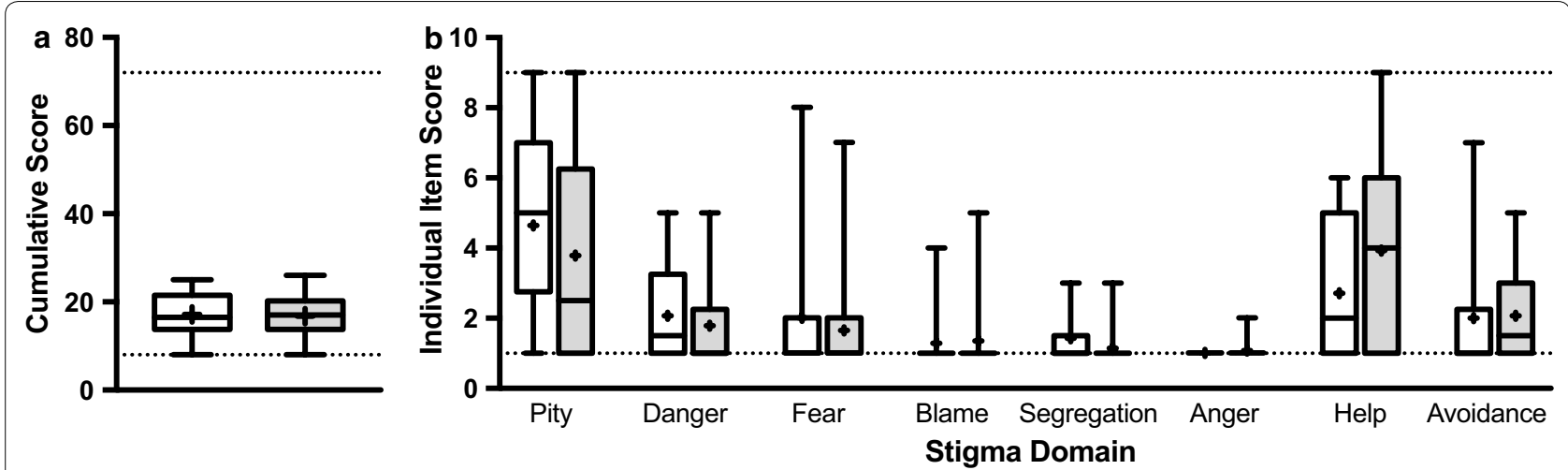

Fig. 2 Adolescent Attribution Questionnaire. Student stigma is low at baseline and remains largely unchanged post-intervention. Pre-scores are white; post-scores are grey; dotted lines indicate minimum and maximum possible score; "+" is the mean. a Cumulative score distribution. b Score distribution for each of the different domains measured

were seen in constructs of pity $(-0.86 \pm 3.18)$ and help $(1.21 \pm 2.19)$ (Fig. 2b). Students scored $17.14 \pm 4.80$ preand $16.79 \pm 4.79$ post- for a matched stigma reduction of $0.36 \pm 4.68$ and an effect size of $d=-0.07$ (Table 4 ). Effect sizes for individual stereotypes are provided in Table 4 for completeness but were heavily influenced by floor effects.

\section{Mental health help-seeking intentions}

Ultimately, behavioral change is the outcome with highest clinical relevance. GHSQ-V data showed student responses trending toward increased hypothetical helpseeking intentions (Fig. 3). Responses became more centralized post-intervention with particular shortening of the interquartile range in the suicidal, substance, and psychosis vignettes. This regression to the mean is likely more representative of actual behavior and important for students who previously indicated a strong reluctance to seek help. Although none of the post-intervention changes were statistically significant under conservative two-tailed analyses, results in depression (Wilcoxon signed rank $\mathrm{p}=0.12 ; \mathrm{d}=0.48$ ) and psychosis (Wilcoxon signed rank $\mathrm{p}=0.11 ; \mathrm{d}=0.53)$ approached statistical significance with additional small to medium effects in anxiety $\mathrm{d}=0.24$ and substance misuse $\mathrm{d}=0.43$ (Table 5). There appeared to be a general shift toward health helpseeking overall with a medium pre-post effect size for heart disease $(\mathrm{d}=0.56)$. Perceived treatment need was high at baseline (79-100\%) and remained largely unchanged post-intervention (86-100\%).

\section{Teacher exit interviews}

Overall, the teachers reported positive perceptions of the unit and of their students' outcomes. The mental health content was relevant, and lessons with active inquiry were especially well received. In retrospect, surveys were not perceived to be the ideal source of data collection, particularly for a population of "reluctant learners" with "years and years of school failure." One suggestion for future data collection was to conduct interviews with

Table 4 Adolescent Attribution Questionnaire (AQ-8-C)

\begin{tabular}{|c|c|c|c|c|c|}
\hline & $\begin{array}{l}\text { Pre- } \\
\text { Average (SD) }\end{array}$ & $\begin{array}{l}\text { Post- } \\
\text { Average (SD) }\end{array}$ & $\begin{array}{l}\text { Difference } \\
\text { Average (SD) }\end{array}$ & $\begin{array}{l}\text { Wilcoxon } \\
\text { p-value }\end{array}$ & d \\
\hline Pity & $4.64 \pm 2.44$ & $3.79 \pm 2.94$ & $-0.86 \pm 3.18$ & 0.13 & -0.32 \\
\hline Dangerousness & $2.07 \pm 1.38$ & $1.79 \pm 1.19$ & $-0.29 \pm 1.27$ & 0.53 & -0.22 \\
\hline Fear & $2.00 \pm 2.04$ & $1.64 \pm 1.60$ & $-0.36 \pm 2.06$ & 1.00 & -0.20 \\
\hline Blame & $1.29 \pm 0.83$ & $1.36 \pm 1.08$ & $0.07 \pm 1.00$ & 1.00 & 0.07 \\
\hline Segregation & $1.43 \pm 0.85$ & $1.14 \pm 0.53$ & $-0.29 \pm 0.73$ & 0.50 & -0.40 \\
\hline Anger & $1.00 \pm 0.00$ & $1.07 \pm 0.27$ & $0.07 \pm 0.27$ & 1.00 & 0.38 \\
\hline Help & $2.71 \pm 1.98$ & $3.93 \pm 3.00$ & $1.21 \pm 2.19$ & 0.06 & 0.48 \\
\hline Avoidance & $2.00 \pm 1.71$ & $2.07 \pm 1.33$ & $0.07 \pm 1.54$ & 1.00 & 0.05 \\
\hline Total & $17.14 \pm 4.80$ & $16.79 \pm 4.79$ & $-0.36 \pm 4.68$ & 0.84 & -0.07 \\
\hline
\end{tabular}

Student stigma is low at baseline and remains largely unchanged post-intervention 


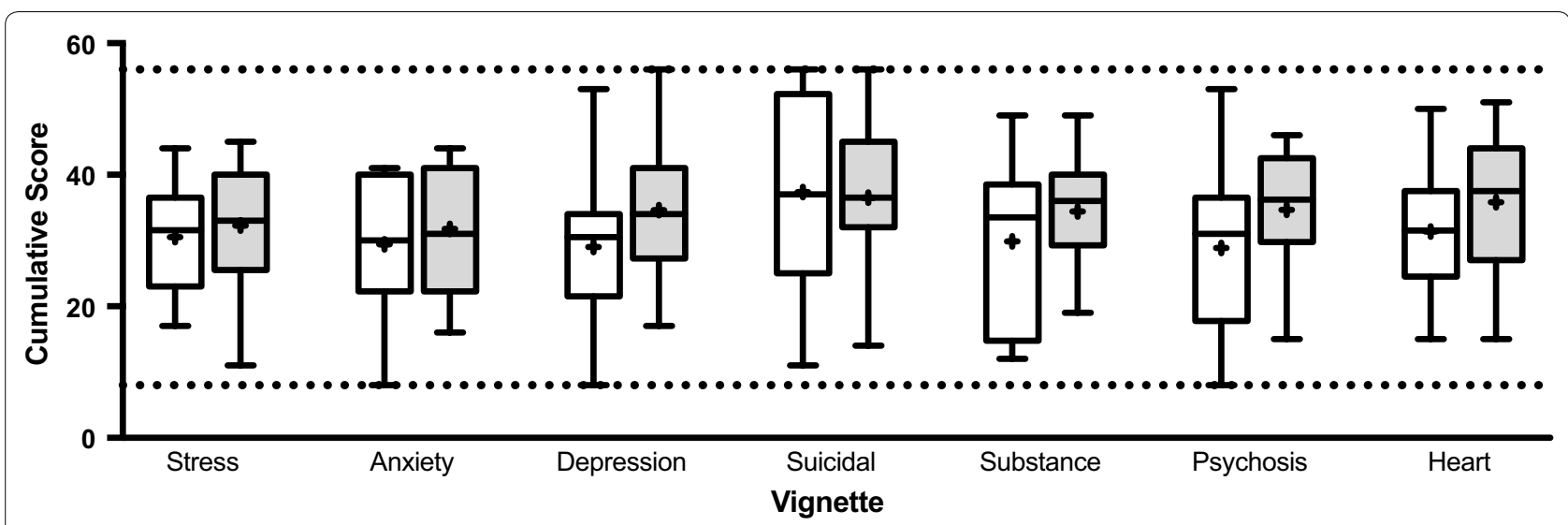

Fig. 3 General Help-Seeking Questionnaire:Vignette Version. Students trend toward more centralized or increased help-seeking post-intervention. Pre-scores are white; post-scores are grey; dotted lines indicate minimum and maximum possible score; " + "is the mean

Table 5 General Help-Seeking Questionnaire Vignette Version

\begin{tabular}{|c|c|c|c|c|c|}
\hline & $\begin{array}{l}\text { Pre- } \\
\text { (Average } \pm \text { SE) }\end{array}$ & $\begin{array}{l}\text { Post- } \\
\text { (Average } \pm \text { SE) }\end{array}$ & $\begin{array}{l}\text { Change } \\
\text { (Average } \pm \text { SE) }\end{array}$ & $\begin{array}{l}\text { Wilcoxon } \\
\text { p-value }\end{array}$ & d \\
\hline Stress & $30.55 \pm 2.27$ & $32.29 \pm 2.53$ & $1.74 \pm 3.13$ & 0.83 & 0.19 \\
\hline Anxiety & $29.43 \pm 2.75$ & $31.79 \pm 2.60$ & $2.36 \pm 3.67$ & 0.79 & 0.24 \\
\hline Depression & $29.00 \pm 3.12$ & $34.64 \pm 3.19$ & $5.64 \pm 3.09$ & 0.12 & 0.48 \\
\hline Suicidal & $37.36 \pm 4.12$ & $36.50 \pm 3.09$ & $-0.86 \pm 2.92$ & 0.28 & -0.06 \\
\hline Substance & $29.86 \pm 3.41$ & $34.43 \pm 2.20$ & $4.57 \pm 3.03$ & 0.21 & 0.43 \\
\hline Psychosis & $28.86 \pm 3.31$ & $34.67 \pm 2.37$ & $5.82 \pm 3.02$ & 0.11 & 0.53 \\
\hline Heart disease & $31.36 \pm 2.71$ & $35.82 \pm 2.90$ & $4.46 \pm 2.95$ & 0.23 & 0.56 \\
\hline
\end{tabular}

Students improve hypothetical help-seeking intentions post-InSciEd Out curriculum

individual students to assemble a student-driven narrative. The teachers felt this might be a more sensitive metric of student growth.

Teachers reported numerous changes in student behaviors post-curricular implementation. Generally, the curriculum elicited high student participation. There were noted improvements to student willingness to risk their voice, both when talking about mental health and when presenting classwork to community members, teachers, and peers. Students were perceived to now have a common language to converse about mental health and consequently shared first/second-hand experiences more openly. Teacher 1 stated: "We would never hear [the students...] in the other years, or even at the beginning of the year [...], own what they had," but "because now they understand that these things all [fall] under mental illness, [...] they [are] more willing to accept that that's what they [have]. There [isn't] that negative stigma attached to it." Teacher 2 reported that students post-unit are "more tolerant of their classmates who have issues" while simultaneously encouraging peers to "do something" by seeking help. The teachers reported beliefs that their students now have a better idea of when to seek help for their mental health.

\section{Discussion}

These preliminary findings show three trends meriting future study. First, at-risk adolescents may fundamentally differ from their peers. Baseline mental health literacy was significantly higher in this sample $(8.14 \pm 2.07)$ when compared to that of a previously published [27], general middle school population $(6.87 \pm 2.30)$ (GraphPad unpaired t-test $\mathrm{p}=0.04$; Table 6). Stigmatization was also lower in this at-risk cohort. One explanation could be prior exposure to the mental health system. Another rationale could be that there is a dimension of stigma unmeasured by the AQ-8-C. Establishing baseline literacy and stigma in this unique adolescent population is important, both to shed light on how to decrease care fragmentation and to tailor future health interventions to the needs of this vulnerable group.

Second, despite low inventory-reported stigma, teacher interviews suggest stigma remains a barrier for at-risk youth. More sensitive metrics, perhaps through 
Table 6 Reformatted Westbrook Mental Health Knowledge Test for Comparison

\begin{tabular}{|c|c|c|c|c|}
\hline & \multicolumn{2}{|l|}{ Pre-test } & \multicolumn{2}{|l|}{ Post-test } \\
\hline & $\begin{array}{l}\text { Correct } \\
\text { n (\%) }\end{array}$ & $\begin{array}{l}\text { Not sure } \\
\text { n (\%) }\end{array}$ & $\begin{array}{l}\text { Correct } \\
\text { n (\%) }\end{array}$ & $\begin{array}{l}\text { Not sure } \\
\text { n (\%) }\end{array}$ \\
\hline Depression is the same thing as being sad. (F) & $11(78.6)$ & $0(0.0)$ & $10(71.4)$ & $1(7.1)$ \\
\hline $\begin{array}{l}\text { Mental illness is like other diseases because a person who has it has symptoms that a doctor can } \\
\text { diagnose. }(T)\end{array}$ & $6(42.9)$ & $4(28.6)$ & $9(64.3)$ & $2(14.3)$ \\
\hline $\begin{array}{l}\text { Individuals who have a family member with a mental illness are more likely to have a mental illness } \\
\text { themselves. }(\mathrm{T})\end{array}$ & $8(57.1)$ & $3(21.4)$ & $9(64.3)$ & $2(14.3)$ \\
\hline The brain of a healthy person works the same as that of a mentally ill person. (F) & $8(57.1)$ & $5(35.7)$ & $11(78.6)$ & $2(14.3)$ \\
\hline $\begin{array}{l}\text { A person who does not get treatment for depression may feel better after a while, but there may be } \\
\text { some long-lasting effects. }(T)\end{array}$ & $10(71.4)$ & $2(14.3)$ & $9(64.3)$ & $4(28.6)$ \\
\hline $\begin{array}{l}\text { How bad a person's mental illness is depends on many things, including his or her genes and family } \\
\text { environment. }(T)\end{array}$ & $9(64.3)$ & $4(28.6)$ & $9(64.3)$ & $5(35.7)$ \\
\hline A person uses his or her brain to learn, but the heart controls a person's feelings. (F) & $7(50.0)$ & $5(35.7)$ & $9(64.3)$ & $5(35.7)$ \\
\hline Most people with mental illness can do normal things like go to school or work at a job. (T) & $12(85.7)$ & $1(7.1)$ & $12(85.7)$ & $2(14.3)$ \\
\hline Treating mental illness can change the way the brain works. ( $T$ ) & $8(57.1)$ & $5(35.7)$ & $8(57.1)$ & $5(35.7)$ \\
\hline People with depression don't need to see a doctor — they just get over it. (F) & $14(100.0)$ & $0(0.0)$ & $12(85.7)$ & $1(7.1)$ \\
\hline Depression is a disease. ( $\mathrm{T}$ ) & $2(14.3)$ & $2(14.3)$ & $1(7.1)$ & $2(14.3)$ \\
\hline There are no treatments that work for most mental illnesses. (F) & $7(50.0)$ & $3(21.4)$ & $8(57.1)$ & $5(35.7)$ \\
\hline Students and other people who have a mental illness can't learn. (F) & $12(85.7)$ & $2(14.3)$ & $13(92.9)$ & $1(7.1)$ \\
\hline \multirow[t]{2}{*}{ Total knowledge score } & Mean (SD) & Median & Mean (SD) & Median \\
\hline & $8.14 \pm 2.07$ & 8.0 & $8.57 \pm 2.71$ & 9.5 \\
\hline
\end{tabular}

Students improve their mental health knowledge on the Westbrook Mental Health Knowledge Test post-intervention. A detailed percentage breakdown is given here for ease of comparability to previous studies

individual interviews, are needed to better capture these students' stories. This adolescent cohort may share more openly in venues prioritizing verbal communication, especially given positive reception to lessons involving open dialogue, project-based learning, and oral presentations. Clever data capture designed to be minimally invasive has the potential to draw out rich stories that cannot be easily gleaned from more traditional methods.

Lastly, this case study demonstrates potential feasibility and acceptability of curricular-based, anti-stigma mental health interventions for at-risk youth. This is an area of research that is sorely lacking in the current evidence base. Preliminary trends toward efficacy in mental health promotion make school-based partnerships a potentially efficient platform for health education dissemination. Mental well-being during childhood and adolescence is often inextricably tied to academic success. As such, schools have a vested interest in fostering open discourse about mental health amongst their students.

This pilot study is limited by its single cohort design and small sample size of a vulnerable population. To minimize risk, teacher exit interviews were conducted in lieu of student interviews, and actual student helpseeking behavior was not measured. An external control was not employed due to the preliminary nature of this study, the school-specific implementation of mental health curriculum, and lack of a comparable peer cohort. Random assignment was likewise not possible given the classroom environment, as InSciEd Out lessons are embedded into existent curricula. Future directions will work toward sample size enlargement facilitating recruitment of an external control, which will aid psychometric testing of existent tools and development of new assessment tools. In addition to this, upcoming studies will work with clinical partners to capture measures of actual student help-seeking behavior. Study metrics will also be monitored longitudinally with follow-up for retention.

\section{Conclusions}

The pilot case study herein underscores the utility and potential of school-based mental health promotion efforts, particularly through InSciEd Out's communitybased framework. Targeted improvements in mental health literacy and moderate improvements in help-seeking intentions were accompanied by large decreases in mental health misconceptions. Inventory-reported stigma was low and largely unchanged. Nevertheless, teacher observations suggested anecdotal evidence of increased student self-identification with mental health diagnoses, openness to share, and peer acceptance.

Early and effective intervention is an undervalued tool for preventing or mitigating the negative, long-term 
consequences of poor health. Improved mental health for all can only be realized if affected individuals and their social support structures have sufficient literacy to recognize and understand mental illness, at least at a basic level. A necessary byproduct of this understanding is that stigma toward mental illness needs to decrease, or become eliminated, such that help-seeking is the norm rather than the exception. As such, anti-stigma interventions deserve heavy focus, particularly in high-risk populations. The students in this study represent a segment of general adolescents with demonstrated need for mental health promotion efforts. Although this study's sample size is small, it is enriched for youth with increased risk of developing mental health issues. These students are difficult to reach in general K-12 populations and represent an underserved segment of adolescents.

Although care must always be exercised when working with vulnerable populations, community programming can no longer ignore at-risk youth simply because such studies are difficult to design and execute. Translational research pushing bedside to curbside has potential to give voice to the experiences and needs of this unique cohort in pursuit of improved mental health for all.

\section{Abbreviations}

InSciEd Out: Integrated Science Education Outreach; WMHKT: Westbrook Mental Health Knowledge Test; AQ-8-C: Adolescent Attribution Questionnaire; GHSQ-V: General Help-Seeking Questionnaire Vignette Version.

\section{Authors' contributions \\ JY headed study design, data collection, data analysis, and drafting of this work. RLC coded transcripts for interview data analysis and aided with critical manuscript revision. SJT, SCE and CP contributed to conception and design of the study and critical revision of the manuscript. All authors read and approved the final manuscript.}

\section{Author details}

${ }^{1}$ Clinical and Translational Science, Mayo Clinic, Rochester, MN, USA. ${ }^{2}$ Postbaccalaureate Research Education Program, Mayo Clinic, Rochester, MN, USA. ${ }^{3}$ Psychiatry and Psychology, Mayo Clinic, Rochester, MN, USA. ${ }^{4}$ Biochemistry and Molecular Biology, Mayo Clinic, Rochester, MN, USA.

\section{Acknowledgements \\ Thanks go to Madeleine E.M. Hammerlund for her help in administration of the mental health surveys, Dr. Ashok Kumbamu for his review of the semi- structured interview questions and insight into qualitative coding methodol- ogy, and Thomas J. LaBounty for his statistical guidance. Additional thanks go out to InSciEd Out team members and especially to the alternative school teacher partners for their support of this project.}

\section{Competing interests}

The authors declare that they have no competing interests.

\section{Availability of data and materials}

The datasets generated and/or analysed during the current study are not publicly available due to privacy agreements made during school board approval but are available from the corresponding author on reasonable request. Copies of all study metrics are available by inquiry.

\section{Consent for publication}

Consent was obtained from the teachers to utilize quotes from their interviews anonymously.

\section{Ethics approval and consent to participate}

The survey and interview portions of this study were approved by the Mayo Clinic Institutional Review Board (IRB) with a waiver of informed parental consent under 45CFR46.116. Classroom data in the misconceptions activity was also collected under normal program evaluation in a study declared exempt by the Mayo Clinic IRB.

\section{Funding}

This publication was made possible in part by CTSA Grant Number UL1 TR000135 from the National Center for Advancing Translational Sciences (NCATS), a component of the National Institutes of Health (NIH). Its contents are solely the responsibility of the authors and do not necessarily represent the official view of the NIH. Additional funding for this work was provided through philanthropic support of InSciEd Out through the Mayo Clinic Office of Development. JY's graduate studies were supported in part by the National Science Foundation's Graduate Research Fellowship Program. RLC's position in the Postbaccalaureate Research Education Program (PREP) is supported in part by NIH grant R25 GM 75148 and SCE's NIH R01 grant 5R01HG006431. RLC is now at the University of Minnesota, Minneapolis, MN, and JY is with Mayo Clinic, Jacksonville, FL.

\section{Publisher's Note}

Springer Nature remains neutral with regard to jurisdictional claims in published maps and institutional affiliations.

Received: 9 February 2018 Accepted: 23 March 2018

Published online: 03 April 2018

\section{References}

1. Vigo $D$, Thornicroft $G$, Atun R. Estimating the true global burden of mental illness. Lancet Psychiatry. 2016;3:171-8.

2. Patel V, Flisher AJ, Hetrick S, McGorry P. Mental health of young people: a global public-health challenge. Lancet. 2007:369:1302-13.

3. Gulliver A, Griffiths KM, Christensen H. Perceived barriers and facilitators to mental health help-seeking in young people: a systematic review. BMC Psychiatry. 2010;10:113.

4. Dalky HF. Mental illness stigma reduction interventions: review of intervention trials. West J Nurs Res. 2012;34:520-47.

5. Jorm AF, Korten AE, Jacomb PA, Christensen H, Rodgers B, Pollitt P. Mental health literacy: a survey of the public's ability to recognise mental disorders and their beliefs about the effectiveness of treatment. Med J Aust. 1997;166:182-6.

6. Jorm AF. Mental health literacy: empowering the community to take action for better mental health. Am Psychol. 2011:67:231-43.

7. Manganello JA, Sentell T, Davis TC. Health literacy, mental health, and adolescents. In: O'Donohue WT, Benuto LT, Tolle LW, editors. Handbook of adolescent health psychology. Springer: New York; 2013. p. 143-51.

8. Bettinghaus EP. Health promotion and the knowledge-attitude-behavior continuum. Prev Med. 1986;15:475-91.

9. Schrader PG, Lawless KA. The knowledge, attitudes, \& behaviors approach: how to evaluate performance and learning in complex environments. Perform Improv. 2004;43:8-15.

10. Wei Y, McGrath PJ, Hayden J, Kutcher S. Mental health literacy measures evaluating knowledge, attitudes and help-seeking: a scoping review. BMC Psychiatry. 2015;15:291. https://doi.org/10.1186/s12888-015-0681-9.

11. Corrigan PW, Morris SB, Michaels PJ, Rafacz JD, Rüsch N. Challenging the public stigma of mental illness: a meta-analysis of outcome studies. Psychiatr Serv. 2012;63:963-73.

12. Wallerstein Nina B, Duran Bonnie. Using community-based participatory research to address health disparities. Health Promot Pract. 2006; 7:312-23.

13. Marsiglia FF, Dustman P, Harthun M, Coyne Ritland C, Umaña-Taylor A. Community-based effectiveness trials as a means to disseminate evidence-based and culturally responsive behavioral health interventions. Health Soc Work. 2017;42:108-16.

14. Lee RM, Gortmaker SL. Health dissemination and implementation within schools. In: Brownson RC, Colditz GA, Proctor EK, editors. Dissemination 
and implementation research in health: translating science to practice. 2nd ed. Oxford: Oxford University Press; 2017. p. 401-16.

15. Mellor C. School-based interventions targeting stigma of mental illness: systematic review. Psychiatr Bull. 2014;38:164-71.

16. Khodyakov D, Mikesell L, Schraiber R, Booth M, Bromley E. On using ethical principles of community-engaged research in translational science. Transl Res J Lab Clin Med. 2016;171(52-62):e1.

17. InSciEd Out. InSciEd Out: we're rebuilding science education from the inside out. https://www.insciedout.org/. Accessed 7 Feb 2018.

18. Pierret C, Sonju JD, Leicester JE, Hoody M, LaBounty TJ, Frimannsdottir KR, et al. Improvement in student science proficiency through InSciEd Out. Zebrafish. 2012;9:155-68.

19. Yang J, LaBounty TJ, Ekker SC, Pierret C. Students being and becoming scientists: measured success in a novel science education partnership. Palgrave Commun. 2016;2:16005.

20. Hostiuc S, Moldoveanu A, Dascălu M-I, Unnthorsson R, Jóhannesson Ól, Marcus I. Translational research —-the need of a new bioethics approach. J Transl Med. 2016;14:16.

21. Koep T, Jenkins S, M Hammerlund M, Clemens C, Fracica E, Ekker S, et al. Promotion of influenza prevention beliefs and behaviors through primary school science education. J Community Med Health Educ. 2016;6:444.
22. Porowski A, O'Conner R, Luo JL. How do states define alternative education? REL 2014-038. 2014.

23. Government of Western Australia. Government of Western Australia: Mental Health Commission. http://www.mentalhealth.wa.gov.au/. Accessed 7 Feb 2018.

24. Pathstone Mental Health. Top 11 myths about mental illness. Shatter the stigma: mend the mind. 2017. https://www.mendthemind.ca/stigma/ top-11-myths-about-mental-illness/. Accessed 7 Feb 2018.

25. U.S. Department of Health and Human Services. Mental health myths and facts. MentalHealth.gov: let's talk about it. 2017. https://www.mentalheal th.gov/basics/mental-health-myths-facts. Accessed 7 Feb 2018.

26. Canadian Mental Health Association. Myths about mental illness. CMHA National. 2018. https://cmha.ca/documents/myths-about-mental-illness. Accessed 7 Feb 2018.

27. Watson AC, Otey E, Westbrook AL, Gardner AL, Lamb TA, Corrigan PW, et al. Changing middle schoolers' attitudes about mental illness through education. Schizophr Bull. 2004;30:563-72.

28. Corrigan PW. A toolkit for evaluating programs meant to erase the stigma of mental illness. Chicago: Illinois Institute of Technology; 2008.

29. Wilson CJ. General Help-Seeking Questionnaire-Vignette Version (GHSQ-V). 2016.

\section{Submit your next manuscript to BioMed Central and we will help you at every step:}

- We accept pre-submission inquiries

- Our selector tool helps you to find the most relevant journal

- We provide round the clock customer support

- Convenient online submission

- Thorough peer review

- Inclusion in PubMed and all major indexing services

- Maximum visibility for your research

Submit your manuscript at www.biomedcentral.com/submit
() Biomed Central 